Peter Philippson

Dreaming in the World 


\section{Impressum}

Psychotherapie-Wissenschaft

ISSN 1664-9583 (Print-Version)

ISSN 1664-9591 (digitale Version)

11. Jahrgang Heft $2 / 2021$

https://doi.org/10.30820/1664-9583-2021-2

info@psychotherapie-wissenschaft.info

www.psychotherapie-wissenschaft.info

\section{Herausgeber}

Schweizer Charta für Psychotherapie in der Assoziation

Schweizer Psychotherapeutinnen und Psychotherapeuten

Geschäftsstelle ASP

Riedtlistr. 8

CH-8006 Zürich

Tel. +41432689300

www.psychotherapie.ch

\section{Redaktion}

Mara Foppoli, Lugano

Lea-Sophie Richter, Zürich

Mario Schlegel, Zürich

Peter Schulthess, Zürich

Hinweise für AutorInnen befinden sich auf der Homepage der Zeitschrift: www.psychotherapie-wissenschaft.info

\section{Verlag}

Psychosozial-Verlag

Walltorstr. 10

D-35390 Gießen

+49642196997826

info@psychosozial-verlag.de

www.psychosozial-verlag.de

\author{
Abo-Verwaltung \\ Psychosozial-Verlag \\ bestellung@psychosozial-verlag.de
}

\section{Bezugsgebühren}

Jahresabonnement 44,90€ (zzgl. Versand)

Einzelheft $24,90 €$ (zzgl. Versand)

Studierende erhalten gegen Nachweis $25 \%$ Rabatt.

Das Abonnement verlängert sich um jeweils ein Jahr, sofern nicht eine Abbestellung bis acht Wochen vor Ende des Bezugszeitraums erfolgt.

ASP-Mitglieder wenden sich wegen des Abonnements bitte direkt an die ASP.

\section{Anzeigen}

Anfragen zu Anzeigen bitte an den Verlag:

anzeigen@psychosozial-verlag.de

Es gelten die Preise der auf www.psychosozial-verlag.de einsehbaren Mediadaten.

ASP-Mitglieder wenden sich bitte direkt an

die ASP-Geschäftsstelle: asp@psychotherapie.ch

\section{Digitale Version}

Die Zeitschrift Psychotherapie-Wissenschaft ist auch online einsehbar: www.psychotherapie-wissenschaft.info

\section{(C) $(1) \Theta$}

Die Beiträge dieser Zeitschrift sind unter der Creative Commons Attribution-NonCommercial-NoDerivs 3.0 DE Lizenz lizensiert. Diese Lizenz erlaubt die private Nutzung und unveränderte Weitergabe, verbietet jedoch die Bearbeitung und kommerzielle Nutzung. Weitere Informationen finden Sie unter: creativecommons.org/licenses/by-nc-nd/3.0/de 


\title{
Dreaming in the World
}

\author{
Peter Philippson
}

Psychotherapie-Wissenschaft 11 (2) 2021 41-46

www.psychotherapie-wissenschaft.info

CC BY-NC-ND

https://doi.org/10.30820/1664-9583-2021-2-41

\begin{abstract}
I think dreams are very important in a number of ways. I share a sense of the significance of dreaming with Sigmund Freud and Fritz Perls. I regularly bring work with dreams into my therapy, training and groupwork as a way that orients our sense of what is happening both individually and collectively. I will write this in two parts. The first part is an overview of how I understand dreams and different ways I have been working with them as a therapist. The second part introduces a way of working with dreams that I have developed in the past few years, that takes both the understanding and the work in a different direction that collapses the strict separation between waking and dreaming.
\end{abstract}

Keywords: dream, artworks, field processes, interpretation, waking dreams, dreams as reality, couples

\section{What is a dream?}

I propose that we understand dreams primarily as artworks, as improvised post-modern theatre pieces written, directed and played by us, with ourselves also primarily as audience! Our dreams span romance, horror and suspense, theatre of the absurd, everyday life, war, and the realms that can be seen as spiritual or transpersonal. We can even produce a series of related artworks, where the subtext involves the movement from one work to the next. Even those who would disapprove of this kind of theatre are also prolific creators in the genre, though they would probably disapprove of their dreaming as well. A dream tells us that we are at heart creative, artistic beings.

Seeing dreams as art hopefully makes us wary of simplistic or reductive searches for meaning, as if Romeo and Juliet is about the dangers of a bad postal system. As Stanislavsky said, theatre is about subtext - you can read the text at home. So in working with dreams, on your own dreams or with a client, we must start by sitting with the subtext and letting it wash over us before we do anything else with it. If the art is not respected, the artist will stop sharing it with you. Dreamwork is slow and calls for our own creativity, not left-brain interpretation for the most part. Interpretation also has the major problem of cultural bias, assuming meanings to be universal and missing the different cultural variations in the significance of symbols and images. Dreams about death, for example, can have very different meanings for people who believe in a life after death than those who do not, and also between those who believe that their life after death will be happy (heavenly) and those who fear it as something terrible (hellish).

The motivation to dream, in good Gestalt Psychology/ Therapy tradition, is usually something that is unfinished and pushing for further expression when the censoring actions of our everyday waking lives are put aside in sleep or dozing. And the two main versions of that unfinished situation underlie the two main Gestalt Therapy approaches to working with dreams.

\section{Dreams as projections}

The classic idea of «unfinished business» of Gestalt theory, based on the principle of Pragnanz, or the Zeigarnik Effect (Zeigarnik, 1927), is an obvious candidate for what motivates our dreaming (it says that the interruption of a task improves the chances that it is remembered). A significant process that is pushing for completion gets acted out in the dream, and the characters and settings of the dream can be treated as projections of possibilities that could allow completion. This was the main way that Fritz Perls worked with dreams, asking the client to speak as the characters of the dream (not just the people or living characters, but also objects, the dream itself, or what was missing (invisible, or surprisingly not present) in the dream. The interactions between those characters, how they support or fight against each other, can also be explored, gaining more of a sense of the whole field of possibilities implied in the dream.

\section{Example}

Client: I dreamed of going into my childhood home and wandering around on my own, feeling the familiar, yet slightly uncomfortable, feel of it. Then I saw a door that I had never seen before. It was small and easy to miss, but I was interested to see what was behind it. I had to stoop down to get through it. I found I was in a bright room with big windows. There were people in there, playing various games. I was not sure whether to join them, though they seemed welcoming.

Therapist: Can you speak as the door? What is the dream from your perspective?

Client: I've always been there, but I am small and so I haven't been noticed. You have to make yourself smaller to be able to go through me without bumping your head. 
Therapist: How would you describe the differences between one side of you and the other?

Client: On one side there is this man on his own wandering round, just observing. On the other side there are people, activities, energy. I'm surprised that the man didn't hear them, I'm not a very soundproof.

From this kind of projection work, the client can come in contact with themes of isolating, not noticing where there are possibilities for connection with life, the idea that he has to make himself smaller to enter the new room.

\section{Dreams as retroflections}

The other approach, favoured by Isadore From, starts with the idea that our dreaming is not inherently separate from the world, but is the beginning of a creative process that finishes in action to actualize the dream. I can dream a building and can then turn it into an actuality, dream of a relationship, say a sexual one, and invite someone to share and actualize the dream with me. This is the Gestalt theory of aggression, that human beings don't passively enter a world, but enter it intentionally and remodel the world to our intention simultaneously with our entering.

In From's approach, a dream is a retroflection of this process of completion in the world, like dreaming of food when I am hungry rather than getting food. From saw dreams the night before coming to therapy as retroflected statements to the therapist, and told the client to find ways to turn that statement outwards. I think this is a rather limited, though sometimes meaningful, application of a very fertile idea, and can lose the artistry in rather banal communications, as in the well-known time when a client brought From a dream he described as «short», and From explored the client's relation to From's short stature. But the whole sense of what the actualization of the dream would be in the world seems to me an exciting approach, and, of course, the working-through of the dream can then be in action rather than in words. It also opens another possibility of working with the dream, of playing with giving the dream a different outcome, and seeing what happens.

Taking the same dream as an example, the therapy could continue in this way:

Therapist: I have an idea. You could experiment with going out of the door of this room, I will stay in here. Then you could come in again, and we can see what happens.

Client: [leaves the room and stays out for a couple of minutes, then knocks on the door]

Therapist: [sits throwing a ball and catching it]

Client: [Knocks again, eventually comes in] I was waiting for you to tell me I could come in. [bewildered and slightly angry]
Therapist: [continues playing with the ball, while smiling at the client, then mimes throwing the ball at the client]

Client: [catches the ball and holds it, still looking bewildered]

Therapist: So once you went out the door, your right to be in the room went away, the door you have walked through many times became a new door, and an obstacle. It seems difficult for you now to answer the question «Do I want to play with you?». And my question is «What doorway will you let me be?»

In this way of working, the dream images are taken as retroflections of the relationship between client and therapist, whose space is it, will I be welcomed, do I want to play, can I allow myself to see the new spaces the therapist could be a doorway to.

\section{Dreams as field expressions}

Both of these ways of working are primarily about dreams as an expression of the client's individual life, yet the Gestalt theory of self is a field-emergent one (Perls, 1978; Philippson, 2001, 2009), and this leads to a number of other possibilities for our explorations of dreams. The «horizon» (Husserl, 1970) of all our acts of consciousness is our multiplicity of possible engagements in the world and with other people whom we know would act differently:

\begin{abstract}
«The perception of a thing is perception of it within a perceptual field. And just as the individual thing in perception has meaning only through an open horizon of «possible perceptions〉 ... it has an external horizon> precisely as a thing within a field of things: and this points finally to the whole sworld as perceptual world ... But in living with one another each can take part in the life of the others. Thus the world exists not only for isolated men but for the community of men; and this is due to the fact that even what is straightforwardly perceptual is communalized» (ibid., pp. 162f.).
\end{abstract}

This horizon is as much part of the ground of the dream as our individual concerns. So in our current world, our dreams can be an expression of the community field in the pandemic as well as of our individual response to it. If the field in which we are engaged is moving towards a new organisation (for example, a family crisis, or a political change in our country or our workplace), that can be expressed in our dreams as images of the new direction, and then can be seen as a predictive dream. But it only makes sense as a prediction if I am taking myself outside the field as an observer, instead of as an integral part of the field, or the intersubjective matrix as Daniel Stern (2004) termed it. Some cultures have traditions for predictive dreaming, which provide culturally-understood symbols by which the outcome of a community process can be given in dreams. 


\section{Working with the dreaming field}

Looking at dreams from this level immediately offers other ways to approach them in our own explorations and in therapy with our clients. When I run multi-day trainings or therapy workshops, I begin each day after the first with an invitation to bring the dreams from the night before. Frequently the dreams people bring are shaped by the group processes and themes in the workshop, and bring new resources to taking those further. Images are often shared in group members' dreams. As people realise this, they get a renewed sense of themselves as part of something wider than themselves, as even images of isolation and non-communication are shared. At this stage, frequently group members who have been sitting silently find a way to join in (I do not push people whose expression is silence to speak, but emphasise that the silence, taken phenomenologically, is their engagement, and the compliant speaking if pushed is going to be less about their being and more about their compliance).

So we can develop a collective dream-story, and ask what the next step of the story would be. Or we could enact the dream, with people taking roles in enactment. If a group member brings the dream which we have been looking at, I would leave space for others to engage with their responses to the dream.

Group member 2: That fits for me in my experience of you. You always show yourself as big and separate, and I don't know how we could have fun together.

Group member 3: I had a similar dream, of finding a sweet-shop, looking through the windows but not going in.

Therapist: What are the games or sweets we might share here? And who is outside the door? And what is stopping us?

Now we can explore themes of play, inhibition, acceptance and rejection together. Group member 2's response is a particularly interesting one, because the style of responding exactly fits with the images, being given from a big, separate and serious place as if to a smaller who has to change to fit in. The big advantage of working this way is that the issue each client brings is not their individual problem to be «fixed", but their version of a dilemma that several people are faced with. The themes of big/ small, acceptance/rejection, play/seriousness, aloneness/ community are much bigger and more universal than the individual.

\section{Interpretation of dreams}

I have said that I don't like the idea of a reductionist assigning of meanings to dreams or dream images. But this field-emergent view of dreams does allow a form of interpretation to be valid. At the level where a dream is an expression of a shared space, the meaning of the dream can organically be clear to all, including the therapist who is also part of the field, and the verbalisation of that shared understanding can then be affirming rather than reducing. It is at this level that shamans tell stories, to express what cannot be put into words, but which are able to be understood by the whole community.

I remember being very busy, and having a dream of a burnt-out shop, all boarded up, with the only thing outside being a calculator that was thrown out of the fire. What I was saying was clear and could be understood by my therapist as a shared experience, and we did not need to perform any further "calculations» on it! In the same way, some dreams are complete in themselves, often dreams of being in a new place, or of being stuck, or of being in a battle, and those dreams can simply be shared and acknowledged or celebrated.

In relation to our dream, I could respond at this interpretational level:

Therapist: I feel excited hearing you tell about finding a new door, a new room, new windows. That feels like you have taken a step forwards. Do you know anything more about that?

Client: The world has been looking a bit brighter to me, and I've been talking to more people.

Therapist: I'm really glad for you. I trust that we can find new places together here.

\section{Multilayered significance of dreams}

We can see already that dreams, like any good artwork, can be taken at many different levels, and approaching them differently brings out a different next moment of the process. There is no «right» or "wrong» way to approach the dream, or it could be said that the "wrong» approach is to have a fixed way to be with it. If the therapist has limited ways to interact with a dream, the dreamer will produce the limited dreams that can be a basis for communication: so Freudian clients have Freudian dreams, Jungian clients have Jungian dreams.

I go back to the idea of entering the dream slowly, open to many possibilities of engagement, sometimes with the client taking the lead, sometimes the therapist. And then what we do becomes in its turn part of the «horizon» of the next night's dream.

\section{The dream as reality}

\section{What is real?}

«Since dreams are experienced in the relative isolation of sleep, they are usually the most original of our psychological experiences. For the typical person, in fact, the dream may be the only state where originality can become manifest ... That which seems absurd, bizarre, or meaningless in dreams only seems so from the older more established points of view and attitudes that still dominate the conscious mind» (Rossi, 1985, pp. 14f.). 
In the preamble to his work with Gloria (https://www. youtube.com/watch?v=it0j6FIxIog), Fritz Perls talks about Gestalt Therapy as «Helping the patient to wake up from the nightmare of his existence.» I think this is a remarkable statement, given in the throwaway form in which many of Perls' most profound ideas are given. It can of course be taken very colloquially, as when we say «Today was a nightmare», and then all Perls' statement means is to help the client have a better day. But the idea of «the nightmare of his existence» is worth staying with as an existential statement, and opens the way to fascinating new ground. Franz Kafka (1915) wrote about a man whose actuality was that he had turned into a giant beetle, but the people around him were not allowing that reality in. Was it a dream that he was a beetle, or was he a beetle dreaming he was a human?

Putting that statement into an expanded form, what would it mean to treat the person's troubled waking life as a dream or nightmare? And conversely, what would it mean to treat the person's dreams as a real expression of themselves? For example, a mild-mannered client brings dreams with a lot of fighting. What if the reality of the person is a fighter, and the mild-mannered presentation is a recurring dream? What would that dream mean? How might I be a therapist with the fighter, and what therapy would the fighter need? What would the client lose by waking up? Who do other people become in the dream (for example, people to be placated or polite to)? What needs fighting over?

Meanwhile, in what the client sees as his/her waking life, there is a repeat of particular kinds of ill-luck or bad relationship or missed opportunities, usually mirroring their experiences in their early life. That is what they have come to expect as their lives, which seems quite different from the lives and expectations of those around them. This is their fate, and nobody can help them. In the language of dreams, we could see this as a recurrent nightmare, although the client sees it as waking reality that they cannot escape from - which is also the sense of being in a dream. They wake up with a feeling of relief that they were «just dreaming», but also know that the next night they will be in the same place again. In the same way, the client leaves one painful relationship and feels relief, but with a knowledge that soon they will be in the same nightmare again, either with the same person or someone similar. Treating such fixed patterns as recurrent dreams allows us to use all the dreamwork methods I outlined in Part I of this article to explore them.

\section{Life and dreaming as art}

«But the self is precisely the integrator ... It is the artist of life» (Perls et al., 1994 [1951], p. 11).

What brings life and dreaming together is artistry. Life and dreams are spontaneous artistic creations of the self, which is also profoundly field-relational. This is not a statement of social construction, which implies that the self is outside the social field and impacted by it in the «pinball» manner that some of Kurt Lewin's (2015) writings suggest. It is rather about self as the «organ» of artistry and creativity of the field. For the artist, the dreaming and the creative action are not divided. The creative artist is never «thrown» into the world, but his/ her entry into a situation is part of the constitution of the situation s/he is entering. By how I walk into a room, loudly or quietly, head down, or head up with a smile or an angry frown (or with a gun or a police uniform or a mop and bucket), I am part of the constitution of the room I discover. That is guaranteed by our neural make-up (Rizzolatti \& Craighero, 2004) and by our social skills. We invite people into our waking dreams, and those who join with us are the ones who accept our invitations. This is the only way in which our lives come to have a coherence and a narrative. Meanwhile our sleeping dreams tell us the unfinished side of those waking dreams, whether that is the irksomeness of what we have frustrated, or the pleasures and possibilities we have given up and alienated from our waking dreams.

So the two, sleeping and waking, are not inherently separate, and the problem arises in the act of separation of the two, so our dreams are never on the way to becoming fulfilled as reality. That does not mean that all dreams need to be looked at: some dreams are not very interesting, in the same way that some waking experiences are not fruitful to explore.

\section{Risks of the reverse process}

There is another side to this: people with the power to induct their community into their dreams, through their charisma or their ruthlessness. Dreams of this sort are dreams of national glory, dreams of secret enemies to be destroyed, of inferior people to be subjugated, dreams of what God commands. In a homophobic society, people report abduction by aliens who subject them to an anal probe (in the comedy science-fiction film Paul, the alien says «It's surprising how little information can be got from an anal probe!»). From this perspective, we could say that the dream images to be worked on are of weakness, lack of importance, secrets, inferiority: these are the dream characters to be welcomed to the therapy.

\section{Application to couples therapy}

I have found that this way of thinking has a useful application to work with constantly quarrelling couples. If the relation to the partner is a recurrent waking dream, to which dreamwork methods can be applied, then the arguments of the partner are significant parts of that dreaming process. I therefore ask the couple to continue the argument, but to take the opposite pole. I have never found that couples have difficulty doing that. I explain it by saying that both partners have both poles, but just as they decide that one person cooks and 
the other washes up, they organise themselves that one partner takes one pole (often around avoiding getting too close or too ordered) and the other takes the other pole (around getting too distant or too disorganised). The dreamwork allows both partners to identify both poles.

\section{Working with the world as a lived dream}

I have found that clients are fascinated by this approach and are very willing to try it. This has led to some very exciting explorations by those clients, where all the ways of working with dreams can be used with their descriptions of their lives (for example their relationships or the way they see other people round them). Example:

Client: I am writing a book, I've been writing it for years, but keep on procrastinating and never get it finished.

Therapist: Can you experiment with saying the same thing as the book?

Client: I am incomplete. I have some good stuff in me, but until he is finished with me I will never see the light of day and nobody will see me.

Therapist: So what do you want to say to your author?

Client: Let me out and let me go! I'm good enough to face the world.

Therapist: Now be the writer.

Client: I don't know that you will be good enough. If I let you go, maybe people will laugh and say it is a bad book.

Therapist: Now be the people laughing and criticising the writer and the book.

Client: Call that a novel? You just think you can write, but you can't.

Therapist: [in dreamwork, it is important to see where the energy is; now we have a committed and energised character] What does it feel like to say that to the writer? You seem to have a lot of energy! What is so important to you?

Client: I don't know - I just don't like bad books.

Therapist: Stay with it, it seems much more important than that.

Client: [silence for a time, and then tears] Things I did were never good enough for my father. When he shouted at me that I had done it badly, he seemed so strong, and I was so weak and helpless. It's always felt stronger to me to criticise than to make something. That's bad, isn't it?

Therapist: I could not get put in the position of critic. I get what you are saying. In a way, it is a perfect short story! Is that the one you want to go on writing?

Client: [Looking startled] The book I'm writing is about someone who thinks he is great, but he isn't!

The therapist then leaves the continuation to the client, who decides to continue the book in a rather different way.

\section{Lived environment as part of the dream}

In Perls' dreamwork, it is not only the living beings that are significant characters in the dream. The places and objects also contribute as backgrounds that give shape and tone to the scene. In the same way, the objects with which a person surrounds him/herself are important parts of the continuity of the waking dream they are living. For the dream to change, the client will have to change the "container» of the dream. Depressed clients coming out of depression will usually need to change what they see when they first of all wake up, which is usually a reflection of their depression (or their depression is a reflection of their environment!). They need to paint the walls a different colour, get new objects that they can engage with, wear different clothes. Sometimes this happens spontaneously, sometimes it can be done as an experiment. They will also find that they are connecting with people differently, and sometimes with different people. This is like the dreamwork method where people consciously change the dream and find a new ending.

\section{Conclusion}

I have presented my account of dreaming and ways of working with dreams. Understanding dreams as artworks seems important, both to allow a slower and less cognitive approach to the dream and the dreamer, but also to see the way dreaming processes are integral parts of the artistry of living our lives, whether we are asleep or awake.

\section{References}

Husserl, E. (1970). The Crisis of European Sciences and Transcendental Phenomenology. Evanston/IL: Northwestern UP.

Kafka, F. (1915). Die Verwandlung. Die Weißen Blätter, 2(10), $1177-1230$

Lewin, K. (2015). Principles of Topological Psychology. Eastford/CT: Martino Fine Books.

Perls, F. (1978) Finding Self through Gestalt Therapy. Gestalt Journal, $I(1), 54-73$.

Perls, F., Hefferline, R. \& Goodman, P. (1994 [1951]) Gestalt Therapy: Excitement and Growth in the Human Personality. New York: Gestalt Journal Press.

Philippson, P. A. (2001). Self in Relation. Highland/NY: Gestalt Journal Press.

Philippson, P.A. (2009). The Emergent Self: An Existential-Gestalt Approach. London: Routledge.

Rizzolatti, G. \& Craighero, L. (2004). The Mirror-Neuron System. Annual Review of Neuroscience, 27, 169-192.

Rossi, E. L. (1985). Dreams \& the Growth of Personality. New York: Brunner/Mazel.

Stern, D. N. (2004). The Present Moment in Psychotherapy and Everyday Life. New York: Norton.

Zeigarnik, B. (1927). Über das Behalten von erledigten und unerledigten Handlungen. Psychologische Forschung, 9, 1-85. 
The Author

Peter Philippson, M.Sc., is a UKCP Registered Gestalt psychotherapist and trainer, a Teaching and Supervising Member of the Gestalt Psychotherapy \& Training Institute UK. He is a founder member of Manchester Gestalt Centre, Full Member of the New York Institute for Gestalt Therapy, Senior Trainer for GITA (Slovenia), faculty member IPsiG (Turin), advisory board member Center for Somatic Studies, founder member of IG-FEST and Past President of the International Association for the Advancement of Gestalt Therapy.

\section{Contact}

Peter Philippson

Manchester Gestalt Centre

7 Norman Road

Manchester, M14 5LF, UK

E-Mail: peterphilippson@gmail.com

Website: www.mgc.org.uk 